\title{
EFFECT OF SAND BYPASSING AT SAKUMA DAM IN TENRYU RIVER AS A MEASURE AGAINST EROSION OF TENRYU RIVER DELTA COAST
}

\author{
Shiho Miyahara ${ }^{1}$, Takaaki Uda ${ }^{2}$, Kou Furuike ${ }^{1}$, Masumi Serizawa ${ }^{1}$, Toshiro San-nami ${ }^{1}$ and \\ Toshinori Ishikawa ${ }^{2}$
}

\begin{abstract}
The long-term evolution of the Tenryu River delta associated with sand bypassing at several dams is investigated using the contour-line-change model considering the change in grain size. The effect of the increase in sediment yield from the river mouth on the nearby coasts is numerically predicted. When the sediment yield is artificially increased, the supplied sediment is mainly deposited around the river mouth, resulting in a large shoreline advance, but it takes a longer time for a sandy beach far from the river mouth to recover. Another measure, such as sand bypassing of the coast, is required to recover sandy beaches downcoast.
\end{abstract}

Keywords: river delta coast; contour-line-change model; Tenryu River; sand bypassing; dam

\section{INTRODUCTION}

The Tenryu River delta has developed owing to the abundant fluvial sediment supplied from the Tenryu River, which originates in the central mountains of Honshu. After the construction of dams in the upstream basin and extensive riverbed excavation, sediment supplied from the river markedly decreased, resulting in the recession of the delta coastline. In recent years, sand bypassing at the Sakuma Dam, the largest dam in this basin, has been planned as a measure against beach erosion of the delta coast. In this plan, a large amount of sand is to be transported through a bypass tunnel to downstream of the dam. To study the effect of this plan, it is necessary to predict the beach changes
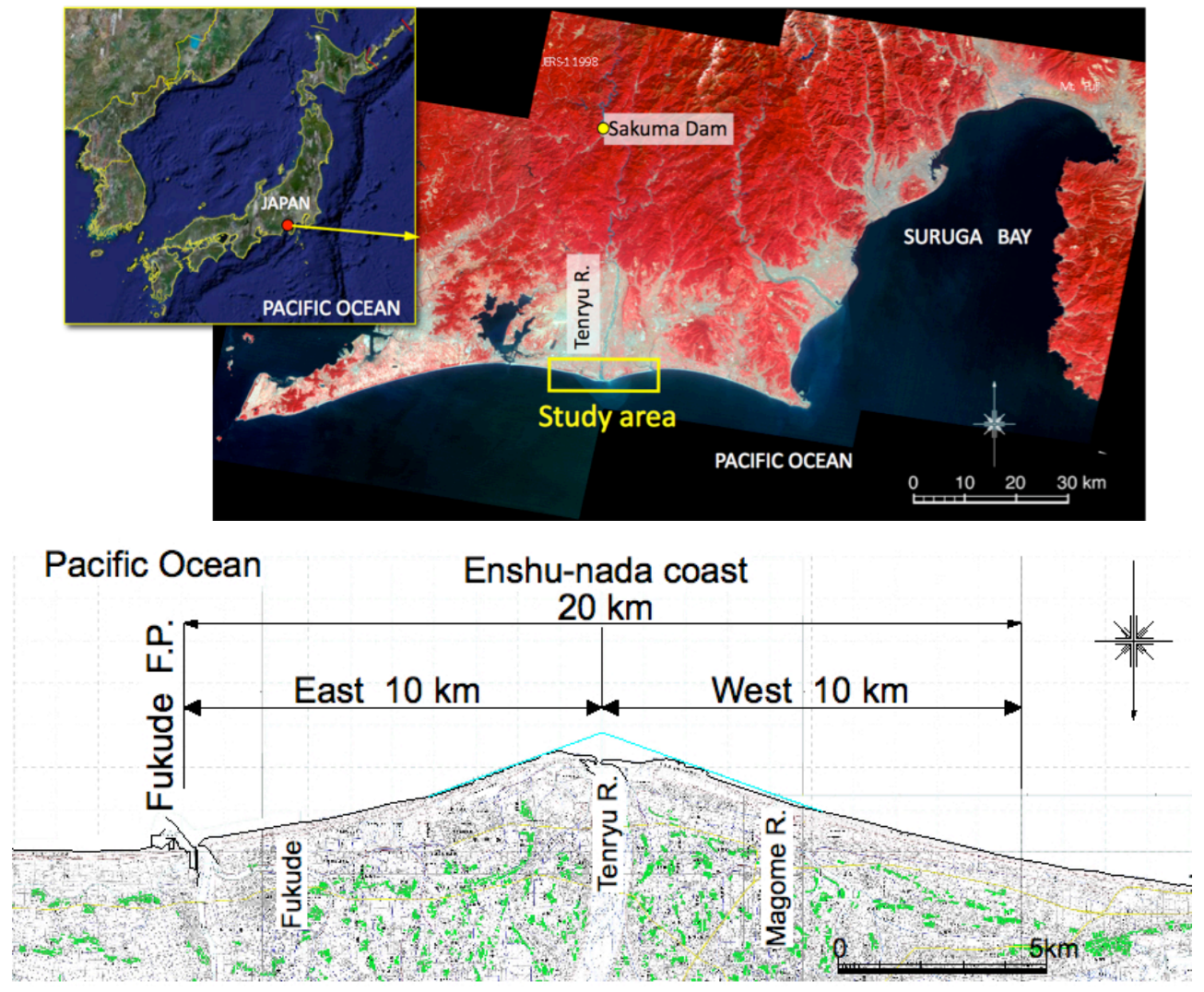

Figure 1. Calculation domain of Tenryu River delta coast.

\footnotetext{
${ }^{1}$ Coastal Engineering Laboratory Co., Ltd., 1-22-301 Wakaba, Shinjuku, Tokyo 160-0011, Japan

${ }^{2}$ Public Works Research Center, 1-6-4 Taito, Taito, Tokyo 110-0016, Japan
} 
along the coast, particularly the recovery of the shoreline, when sand bypassing is carried out in the upstream region of the river. In this study, the topographic changes of the entire river delta coast are predicted using the contour-line-change model, in which the effect of grain size changes is taken into account. First, the river delta in 1890 under natural conditions is reproduced given the parallel contours and fluvial sediment supply, considering a sufficiently long period of 9000 years for the evolution of the fluvial delta. Then, the beach changes are predicted after the sediment supply from the river is decreased. Finally, the beach changes after the increase in sediment supply owing to sand bypassing at the dams are predicted. The study area is the Enshu-nada coast with a stretch of a $20 \mathrm{~km}$ length extending on both sides of the Tenryu River delta facing the Pacific Ocean (Fig. 1), and the duration of predicting the topographic changes is set to be 100 years from 2005. In this area, the Tenryu River flows into the ocean in the central part, and Fukude fishing port breakwater and the river mouth jetty of the Magome River extend in the eastern and western parts, respectively.

\section{LONG-TERM SHORELINE RECESSION OF TENRYU RIVER DELTA}

The geographical map of the Tenryu River delta coast was first produced in 1890, and the shoreline in this year can be used as a reference for the analysis of long-term shoreline evolution. Then, the shoreline configurations in 1962 and 2005 can be used as typical cases after the sediment supplied from the river had markedly decreased owing to the extensive river bed excavation and the construction of dams. Figure 2 shows the shoreline changes up to 2005 with reference to that in 1890 . The shoreline of the Tenryu River delta had retreated by a maximum of $600 \mathrm{~m}$ in a triangular shape with respect to the centerline of the river mouth delta by 2005 , owing to the decreased supply of sediment, whereas the shoreline advanced in parallel west of $X=10 \mathrm{~km}$ and east of $X=-5 \mathrm{~km}$. This is because even though the shoreline retreats in the central part of the river delta, it continues to advance far from the river mouth owing to the depositional effect of the shoreline during the deformation of a river delta coastline (Furuike et al., 2009). Furthermore, the shoreline has a discontinuity on the Ryuyo coast and at the Magome River mouth, where 5 and 22 detached breakwaters were constructed, respectively, as seen in the shoreline changes up to 2005.

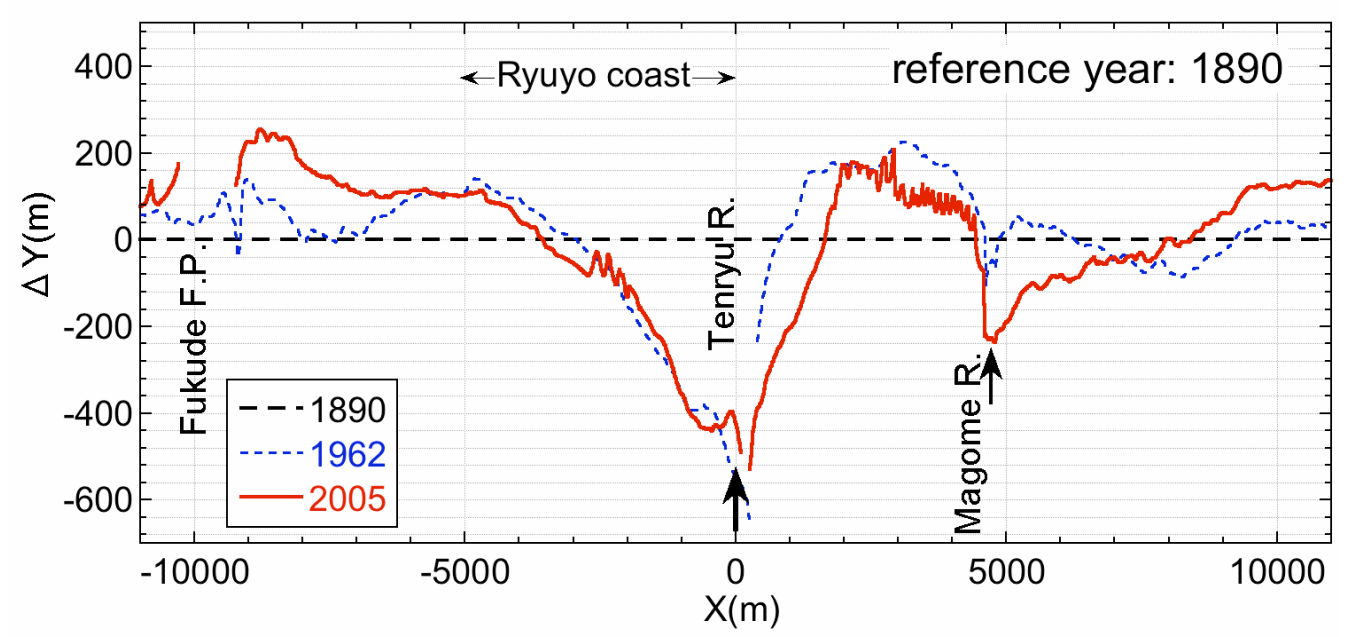

Figure 2. Shoreline changes of Tenryu River delta coast with reference to that in 1890.

Figure 3 shows the longshore distribution of beach width measured offshore from the coastal dike or the seawall. The beach width in 2005 was essentially 0 on the right bank of the Magome River mouth and the east end of the detached breakwaters of the Ryuyo coast. Thus, the present Enshunada coast significantly differs from the natural coastline of the past when much fluvial sediment supplied from the Tenryu River had been transported by longshore sand transport. The many coastal protection facilities constructed along the shoreline have resulted in discontinuity of the shoreline at such locations and the beach width is narrowed downcoast of these structures. 


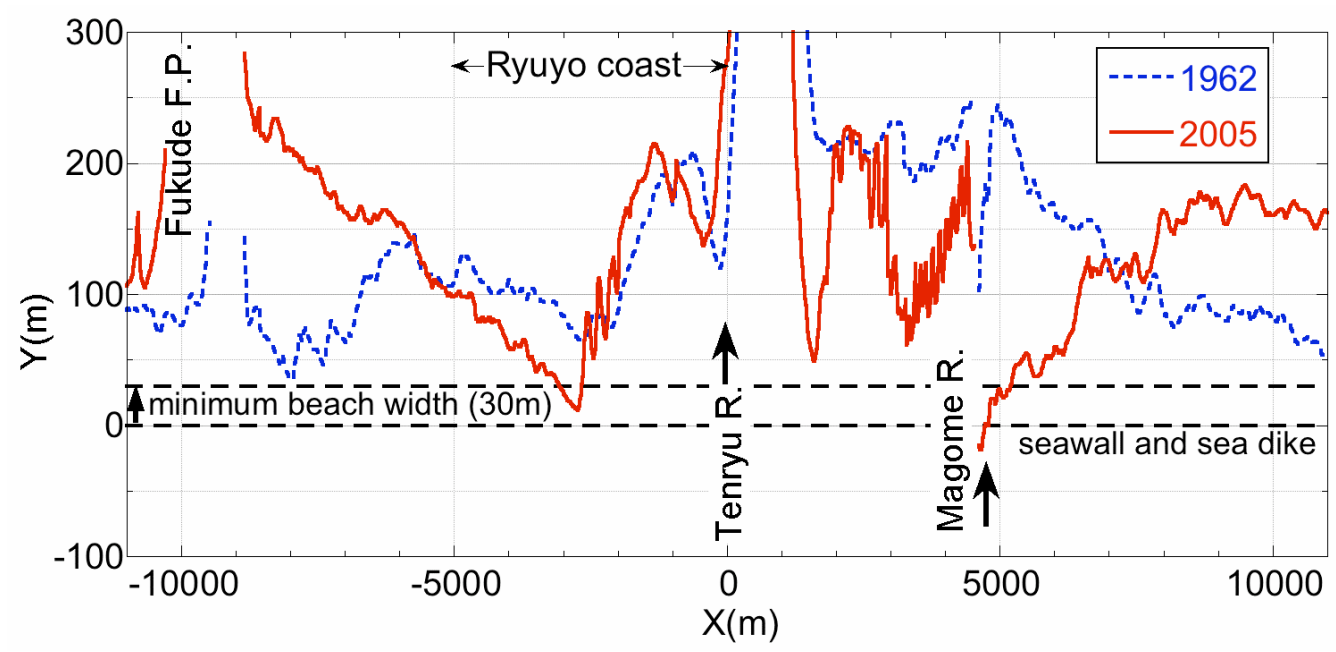

Figure 3. Longshore distribution of beach width.

\section{NUMERICAL MODEL}

A numerical model developed on the basis of the contour-line-change model proposed by Serizawa et al. (2003) was used. Let the $x$ - and $z$-axes be the longshore distance and the depth, respectively, and $Y$ is the offshore distance to a specific contour line. The cross-shore transport of sand composed of mixed grain sizes can be modeled by expanding the concept of single grain size. The sorting of grain size populations, such as those of fine sand, medium and coarse sand, and gravel, can be modeled by introducing the equilibrium slope angle $\beta_{c}{ }^{(k)}$ which corresponds to each grain size population $k$. In this case, a grain size population is assumed to have a single equilibrium beach slope with a characteristic grain size $d^{(k)}$, for example, the median diameter of the grain size population.

By assuming that the mobility of sand of each grain size population by cross-shore movement under the same wave conditions is the same as that of longshore sand transport, the coefficient of the sediment transport rate according to the grain size $d^{(k)}$, which was given by Kamphius et al. (1986) and Kumada et al. (2003), is introduced. Furthermore, assuming that the ratio of the exposed area of each grain size population to the entire sea bottom area is equal to the content of each size population in the exchange layer $\mu^{(k)}$ (where $k=1,2, \cdot \cdots, N$ ), the cross-shore sand transport rate of each grain size population $q_{z}{ }^{(k)}$ is derived by a method similar to that of Uda et al. (2004).

$\underline{\text { Cross-shore sand transport }}$

$$
\begin{gathered}
q_{z}^{(k)}=\mu^{(k)} \cdot \varepsilon_{z}(z) \cdot \gamma \cdot K_{1}^{(k)} \cdot \\
\left(E C_{g}\right)_{b} \cos ^{2} \alpha_{b s} \sin \bar{\beta} \cdot\left(\cot \beta / \cot \beta_{c}^{(k)}-1\right) \\
; k=1,2, \ldots, N \\
K_{1}^{(k)}=\frac{A}{\sqrt{d^{(k)}}} \\
\cot \beta=-\partial Y / \partial z \\
\varepsilon_{z}(z)= \begin{cases}\left(2 / h_{C}^{3}\right)\left(h_{C} / 2-z\right)\left(z+h_{C}\right)^{2}, & -h_{C} \leq z \leq h_{R} \\
0, & z \leq-h_{C}, z \geq h_{R}\end{cases}
\end{gathered}
$$

Here, $q_{z}^{(k)}(k=1, \cdots, N)$ is the cross-shore sand transport per unit length in the longshore direction for each grain size population, $\mu^{(k)}$ is the content of each grain size population $(k)$ in the exchange layer of 
sand, $\varepsilon_{z}(z)$ is the depth distribution of the sand transport given by Uda and Kawano (1996), and $d^{(k)}$ is a typical grain size of the grain size population. $A$ is a coefficient that depends on the physical conditions of the beach, $d^{(k)}$ in Eq. (2) has a unit of $\mathrm{mm}, K_{1}{ }^{(k)}$ is the coefficient of longshore sand transport, $\gamma$ is the ratio of the coefficient of cross-shore sand transport to the coefficient of longshore sand transport, and expresses the mobility of cross-shore sand transport relative to that of longshore sand transport, $\alpha_{b s}$ is the angle between the wave crest line at the breaking point and each contour line, and $\beta$ is the beach slope angle at each contour line. $\bar{\beta}$ is the average beach slope angle between the berm height $h_{R}$ and the depth of closure $h_{c}$, and $\beta_{c}{ }^{(k)}$ is the equilibrium beach slope angle. When the beach slope becomes steeper than the angle of repose of sand, sand is transported offshore by gravity. By this procedure, we can calculate the formation of a scarp in a zone larger than the berm height $h_{R}$ and the sinking of sand in a zone larger than the depth of closure $h_{c}$.

Longshore sand transport

$$
\begin{aligned}
& q_{x}^{(k)}=\mu^{(k)} \cdot \varepsilon_{z}(z) \cdot K_{1}^{(k)} \cdot\left(E C_{g}\right)_{b} \cdot \\
& \left(\cos \alpha_{b s} \sin \alpha_{b s}-\xi \frac{1}{\tan \beta} \cdot \cos \alpha_{b s} \cdot \frac{\partial H_{b}}{\partial x}\right)
\end{aligned}
$$

Here, $q_{x}^{(k)}(k=1, \cdots, N)$ is the longshore sand transport per unit depth for each grain size population, $\varepsilon_{z}(z)$ is the depth distribution of longshore sand transport, and $\xi$ is the constant given by $K_{2}{ }^{(k)} / K_{1}{ }^{(k)}$, which depends on the physical conditions of the beach, where $K_{2}{ }^{(k)}$ is a function of $K_{1}{ }^{(k)}$ and is equivalent to the coefficient of Ozasa and Brampton (1980). $\tan \beta$ is the beach slope in the surf zone and $H_{b}$ is the breaker height.

$\underline{\text { Mass conservation for each grain size }}$

$$
\begin{gathered}
\frac{\partial y^{(k)}}{\partial t}=-\frac{\partial q_{x}^{(k)}}{\partial x}-\frac{\partial q_{z}^{(k)}}{\partial z} \\
; k=1,2, \ldots, N
\end{gathered}
$$

The total contour line change at a certain position is determined by the summation of the contour line changes of all grain size populations at that position.

$$
\frac{\partial Y}{\partial t}=\sum_{k=1}^{N} \frac{\partial y^{(k)}}{\partial t}
$$

Change in content of each grain size population

$$
\begin{aligned}
\frac{\partial \mu^{(k)}}{\partial t} & =\frac{1}{B}\left\{\frac{\partial y^{(k)}}{\partial t}-\frac{\partial Y}{\partial t} \cdot \mu^{(k)}\right\} \\
; k & =1,2, \ldots, N .
\end{aligned}
$$

The content of each grain size population in the new exchange layer formed during erosion is expressed as

$$
\frac{\partial \mu^{(k)}}{\partial t}=\frac{1}{B}\left\{\frac{\partial y^{(k)}}{\partial t}-\frac{\partial Y}{\partial t} \cdot \mu_{B}^{(k)}\right\}
$$

where $\mu_{B}^{(k)}$ is the content of each grain size population on the sandy beach landward of the initial exchange layer. The width $B$ of the exchange layer is determined with reference to the mixing depth reported by Kraus (1985). The above-mentioned equations were solved simultaneously.

\section{CONDITIONS OF FLUVIAL SEDIMENT SUPPLY}

In this study, three-dimensional changes of the delta coast are predicted given the initial and boundary conditions, including the grain size composition of sand supplied from the river mouth. The 
timescale for predicting shoreline changes is taken to be 100 years from 2005, and the topographic changes of the $20-\mathrm{km}$-long coastline are numerically predicted.

The Chubu Regional Construction Bureau (http://www.cbr.mlit.go.jp/) carried out a onedimensional calculation of riverbed changes and concluded that although the fluvial sand supply from the Tenryu River was $9.4 \times 10^{5} \mathrm{~m}^{3} / \mathrm{yr}$ before the construction of dams and river bed excavation, it was reduced to $2.4 \times 10^{5} \mathrm{~m}^{3} / \mathrm{yr}$ after those activities, suggesting that the fluvial sand supply was reduced to a $25.5 \%$ of the natural sand supply. On the other hand, $6.0 \times 10^{5} \mathrm{~m}^{3} / \mathrm{yr}$ of sediment yield can be estimated from the analysis of the development of the fluvial fan of the Tenryu River during the past $10^{4}$ years (Uda et al., 2008). This sediment yield considers only the grain size component useful for the formation of a sandy beach, that is, larger than approximately $0.1 \mathrm{~mm}$, and excludes silt and mud components, which are transported in the suspension as wash load, in total sediment yield. Uda et al. (2008) predicted the beach changes on the west coast of the Tenryu River mouth, assuming that the sediment yield was reduced from $6.0 \times 10^{5} \mathrm{~m}^{3} / \mathrm{yr}$ to 0 after the construction of dams and river bed excavation and that half the total sediment yield contributed to the west coast, and concluded that reasonable results can be obtained under these conditions.

In the fluvial sediment supply estimated by a one-dimensional calculation of riverbed changes, it was assumed that sediment yield from the river basin before the construction of dams was reduced to that from the residual basin in which the upstream basin of the dams was cut. However, the appropriateness of this estimation has not yet been verified from the change in sand volume measured in a certain period around the river mouth. Therefore, the absolute value of sediment yield before the construction of dams is considered to include some uncertainty, but the ratio of the sediment yield before and after the construction of dams, $25.5 \%$, is considered to have a higher reliability. Therefore, the fluvial sediment supply from the river is assumed to be $6.0 \times 10^{5} \mathrm{~m}^{3} / \mathrm{yr}$ before the construction of dams and extensive riverbed mining, which was estimated from the evolution of the Tenryu fluvial delta (Uda et al., 2008). For the sediment yield after those activities, we assume that the $25.5 \%$ ratio of the sediment yield between the watershed areas downstream and upstream of the dams is maintained. Then, the sediment yield of $1.5 \times 10^{5} \mathrm{~m}^{3} / \mathrm{yr}$ is calculated by multiplying $6.0 \times 10^{5} \mathrm{~m}^{3} / \mathrm{yr}$ with this ratio.

\section{CALCULATION CONDITIONS}

A river delta that has developed over a long time under the premise of sand supply from a river has the feature that the shoreline advances at a constant velocity corresponding to the sand supply. When sand is uniformly extracted at a rate per unit length of the shoreline along the entire shoreline, where the sum of these rates is equal to the total inflow, then we can predict the gradually advancing river delta topography (Furuike et al., 2009). The dynamically stable topography of the Tenryu River delta in 1890 was first reproduced using this procedure and given parallel contours and a sediment supply of $6.0 \times 10^{5} \mathrm{~m}^{3} / \mathrm{yr}$ during 9000 years. Then, this predicted topography was adopted as the initial topography. The sediment supply corresponding to each grain size population during this period is $3.3 \times 10^{5} \mathrm{~m}^{3} / \mathrm{yr}$ for fine sand $(0.1 \mathrm{~mm} \leq d \leq 0.25 \mathrm{~mm}), 2.6 \times 10^{5} \mathrm{~m}^{3} / \mathrm{yr}$ for medium sand $(0.25 \mathrm{~mm} \leq d \leq 0.85 \mathrm{~mm})$ and $1.0 \times 10^{4} \mathrm{~m}^{3} / \mathrm{yr}$ for coarse sand $(d \leq 0.85 \mathrm{~mm})$.

The Sakuma Dam was completed in 1956, and therefore, subsequently, sediment supply after 1956 was reduced to $1.5 \times 10^{5} \mathrm{~m}^{3} / \mathrm{yr}$ (fine sand: $5.0 \times 10^{4} \mathrm{~m}^{3} / \mathrm{yr}$, medium sand: $9.0 \times 10^{4} \mathrm{~m}^{3} / \mathrm{yr}$ and coarse sand: $1.0 \times 10^{4} \mathrm{~m}^{3} / \mathrm{yr}$ ). Finally beach changes up to 2005 were predicted. The equilibrium slope corresponding to each grain size population was assumed to be $\tan \beta=1 / 100$ for fine sand, $\tan \beta=1 / 40$ for medium sand and $\tan \beta=1 / 20$ for coarse sand. Other calculation coefficients are shown in Table 1 . The sediment supply corresponding to each grain size population shown in Table 1 is the mean value averaged over 100 years.

After the reproduction calculation, cases $1-5$, in which the rates of total sediment supply are $0,2.6$, $3.3,3.9$ and $5.2 \times 10^{5} \mathrm{~m}^{3} / \mathrm{yr}$, respectively, were calculated with the components shown in Table 2 . These conditions were determined on the basis of the planning of the Chubu Regional Construction Bureau (http://www.cbr.mlit.go.jp/).

For the boundary conditions of longshore sand transport at both ends of the calculation domain, $Q_{\text {out }}$ is set to be $1.5 \times 10^{5} \mathrm{~m}^{3} / \mathrm{yr}$ (Uda et al., 2008) with the same contents of grain size at both boundaries. The incident wave angle of $20^{\circ}$ to the direction normal to the initial shoreline was assumed on both sides of the river delta coast. 


\begin{tabular}{|c|c|}
\hline \multicolumn{2}{|r|}{ Table 1. Calculation conditions. } \\
\hline Study area & Coastline with $20 \mathrm{~km}$ stretch on both sides of Tenryu River mouth \\
\hline Initial bathymetry & Straight parallel contours \\
\hline Incident wave conditions & $\begin{array}{l}\text { Energy-mean equivalent significant wave height } H=1.6 \mathrm{~m} \\
\text { Wave period } T=7 \mathrm{~s} \\
\text { Wave direction } \mathrm{S} \\
\text { Incident wave angle of } 20^{\circ} \text { to initial shoreline } \\
S_{\max }=10\end{array}$ \\
\hline Water level condition & Mean sea level \\
\hline Calculation range & Between $-h_{c}$ and $h_{R} ; h_{c}:$ depth of closure; $h_{R}:$ berm height \\
\hline Mesh size & $\Delta x=100 \mathrm{~m}$ and $\Delta z=1 \mathrm{~m}$ \\
\hline Time step & $\Delta t=200 \mathrm{hrs}$ \\
\hline Calculation steps & 43.8 steps/yr \\
\hline $\begin{array}{l}\text { Grain size conditions } \\
\text { Equilibrium slope }\end{array}$ & $\begin{array}{ll}\text { Grain size population } 1\left(d_{50}=0.25 \mathrm{~mm}\right) & \tan \beta_{c}=1 / 100 \\
\text { Grain size population } 2\left(d_{50}=0.425 \mathrm{~mm}\right) & \tan \beta_{c}=1 / 40 \\
\text { Grain size population } 3\left(d_{50}=2.0 \mathrm{~mm}\right) & \tan \beta_{c}=1 / 20\end{array}$ \\
\hline Exchange layer width & $50 \mathrm{~m}$ \\
\hline Initial content & $\mu_{1}=0.483, \mu_{2}=0.483, \mu_{3}=0.033$ \\
\hline $\begin{array}{l}\text { Coefficient of longshore } \\
\text { sand transport }\end{array}$ & $\begin{array}{l}K_{x}=A / \sqrt{d_{50}}, \mathrm{~A}=0.0220 \\
K_{2}=1.62 K_{x}(\text { Ozasa and Brampton, 1980) }\end{array}$ \\
\hline $\begin{array}{l}\text { Coefficient of cross-shore } \\
\text { sand transport }\end{array}$ & $K_{\mathrm{z}}=0.15 K_{x}$ \\
\hline $\begin{array}{l}\text { Critical slope on land and } \\
\text { sea bottom }\end{array}$ & $1 / 2$ and $1 / 3$ \\
\hline $\begin{array}{l}\text { Boundary condition of } \\
\text { longshore sand transport }\end{array}$ & $\begin{array}{l}Q_{\text {out }}=1.5 \times 10^{5} \mathrm{~m}^{3} / \mathrm{yr} \text { (Uda et al., 2008) with content of grain size at } \\
\text { both boundaries } \\
Q_{z}=0 \text { at shoreward and seaward ends }\end{array}$ \\
\hline
\end{tabular}

\begin{tabular}{|l|c|c|c|c|}
\hline \multicolumn{5}{|c|}{ Table 2. Sediment supply corresponding to each grain size population. } \\
\hline Case & fine sand & medium sand & coarse sand & total \\
\hline 1 (no measures) & 5 & 8 & 1 & 15 \\
2 & 14 & 11 & 1 & 26 \\
3 & 19 & 14 & 1 & 33 \\
4 & 21 & 17 & 1 & 39 \\
5 & 28 & 24 & 1 & 52 \\
\hline
\end{tabular}

\section{REPRODUCTION OF RIVER DELTA COAST}

Figure 4(a) shows the reproduced topography of the river delta coast in 1890 given the parallel contours and sediment inflow during 9000 years, along with the measured shoreline in 1890. A river delta coast has developed as a result of the sediment supply from the Tenryu River, and the contour lines become triangular with respect to the centerline of the mouth. The predicted and measured shorelines in 1890 are in good agreement. Examining the protruded topography of the river delta in detail, it is found that although the beach slope between the land and $-3 \mathrm{~m}$ is steep, the offshore slope becomes gentle because coarse sand with a larger equilibrium slope is deposited on the foreshore, whereas fine sand with a smaller equilibrium slope is deposited in the offshore zone.

Given the 1890 topography shown in Fig. 4(a) as the initial condition, the topography in 2005 was predicted by reducing the sediment supply to $1.5 \times 10^{5} \mathrm{~m}^{3} / \mathrm{yr}$ after 1956 (Fig. 4(b)). The contour lines of the river delta coast, which protruded in 1890, significantly retreated at the apex with the decrease in sediment supply, and simultaneously, the effect of several coastal structures on the beach topography appeared, resulting in a discontinuous shoreline.

The shoreline change up to 2005 , with reference to that in 1890 , is shown in Fig. 5. Because the detached breakwaters and a training jetty of the Magome River blocked westward longshore sand transport, the shoreline significantly retreated immediately west of the Magome River mouth, whereas the shoreline simultaneously advanced west of the erosion zone. The coastline east of the river mouth 
advanced over an extensive area updrift of Fukude fishing port because of the obstruction of eastward longshore sand transport by the fishing port breakwater. The measured and predicted shoreline changes are in good agreement.
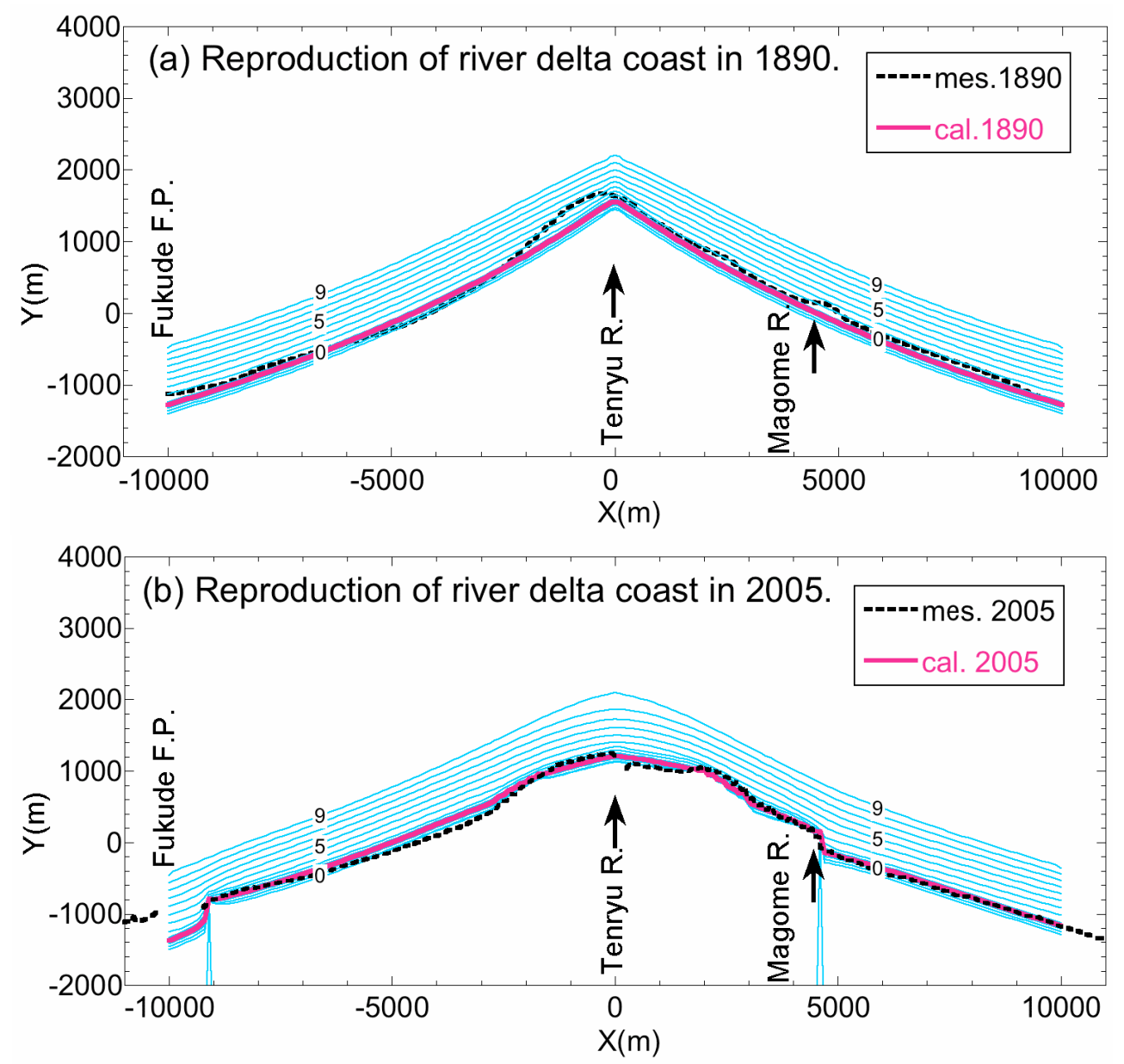

Figure 4. Reproduction of river delta coast in 1890 and 2005.

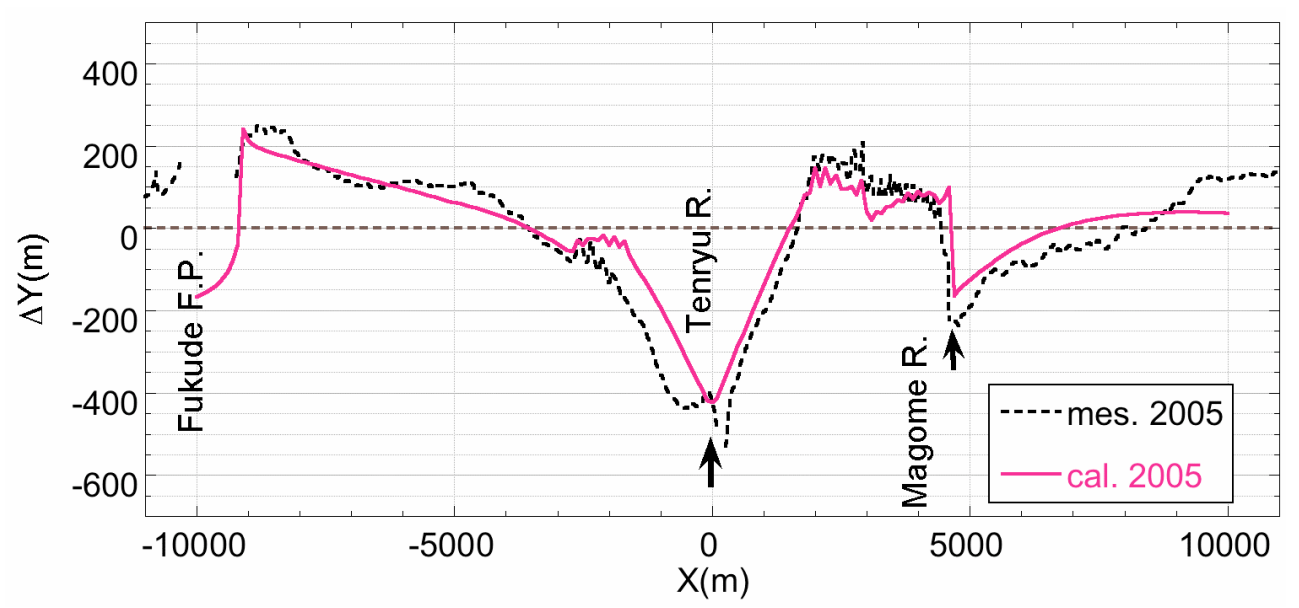

Figure 5. Measured and predicted shoreline changes with reference to that in 1890. 

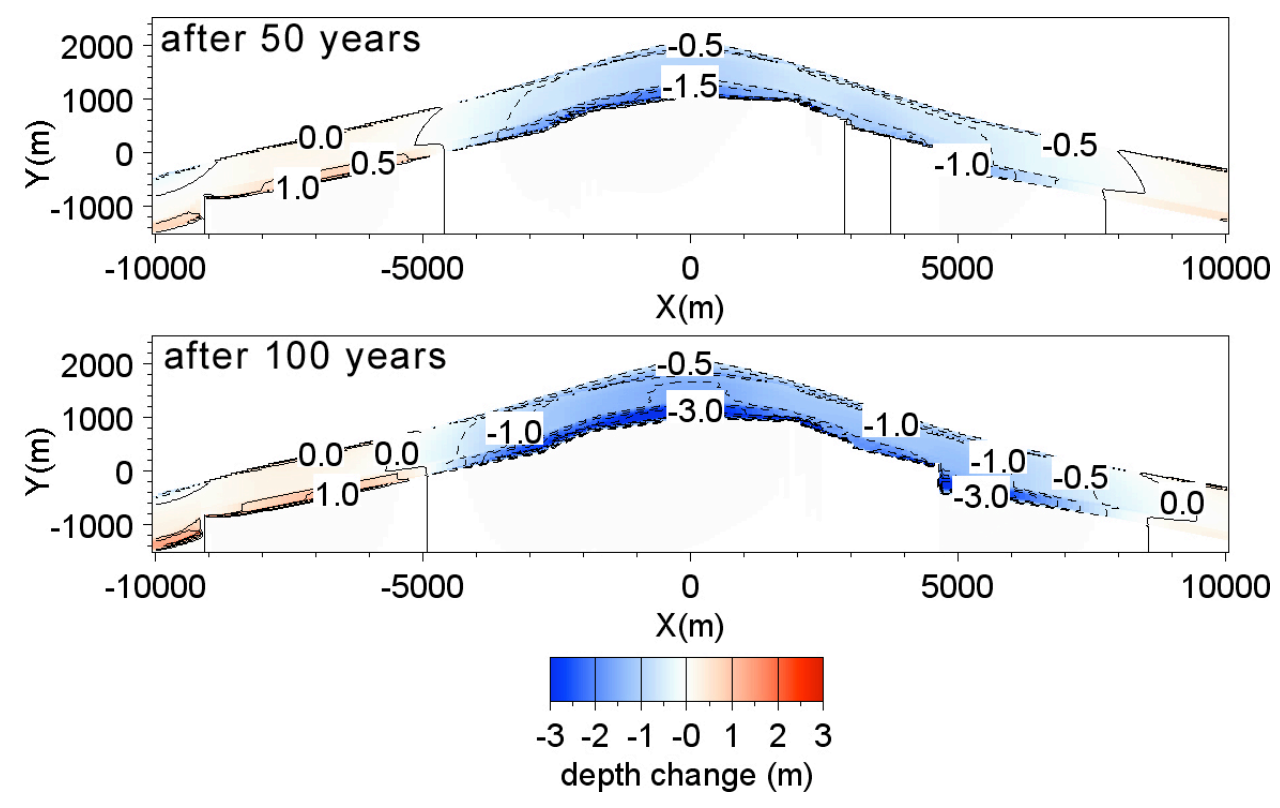

Figure 6. Topographic changes around river delta coast in case 1 with no measures adopted.
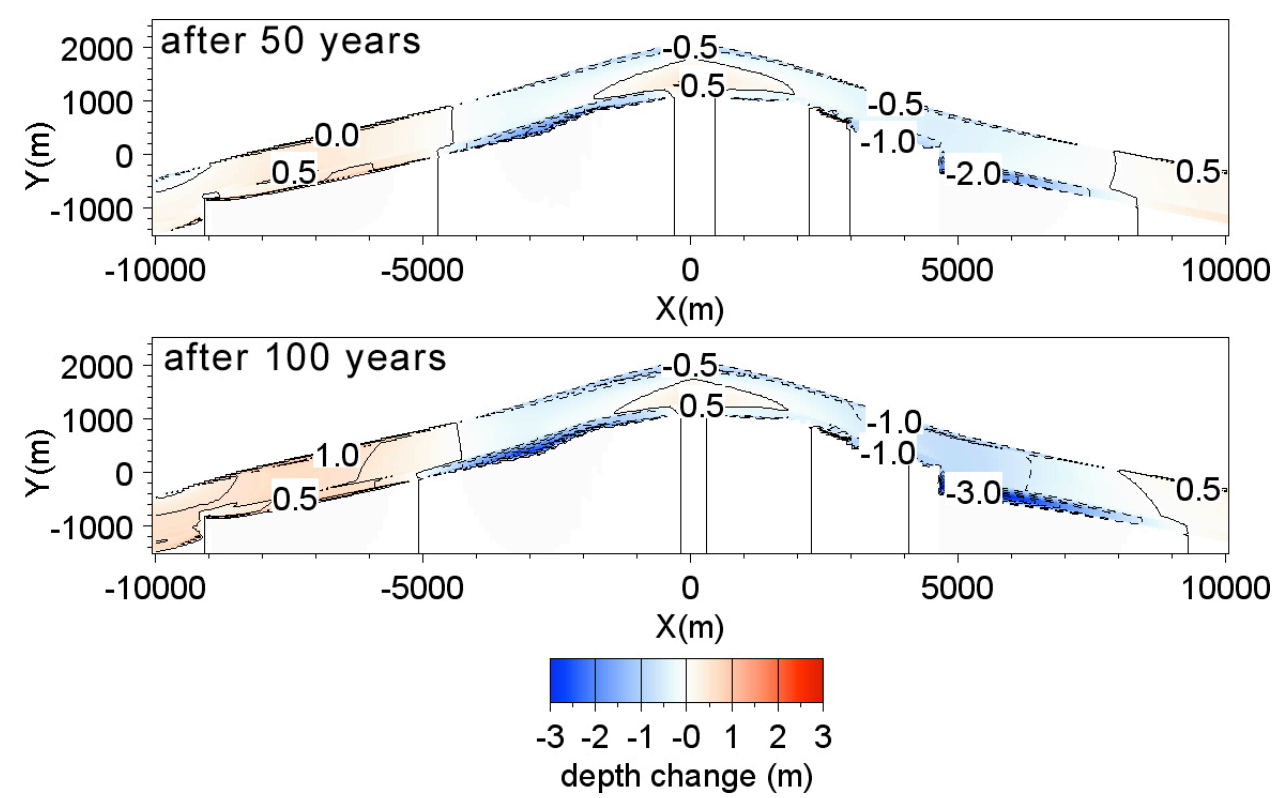

Figure 7. Topographic changes around river delta coast in case 2.

\section{EFFECT OF SAND BYPASSING AT DAMS}

The topographic changes in cases 1-5 are compared. First, Figure 6 shows the predicted bathymetric changes after 50 and 100 years in case 1 with no measures adopted. In this case, beach erosion becomes increasingly severe on both sides of the river delta, resulting in an increase in water depth, although the zone up to $4 \mathrm{~km}$ west of the fishing port becomes locally accretive owing to the obstruction of longshore sand transport by the fishing port breakwater. In the area west of the river mouth, severe erosion comparable to that at the Tenryu River mouth occurs, particularly west of the Magome River mouth, after 100 years because of the blockage of longshore sand transport by the Magome river jetty and detached breakwaters. Note that severe erosion occurs in the vicinity of the shoreline.

Figure 7 shows the predicted topographic changes in case 2, in which sediment with $55 \%$ fine sand, $43 \%$ medium sand and $2 \%$ coarse sand is supplied at a rate of $2.6 \times 10^{5} \mathrm{~m}^{3} / \mathrm{yr}$. Compared with the 

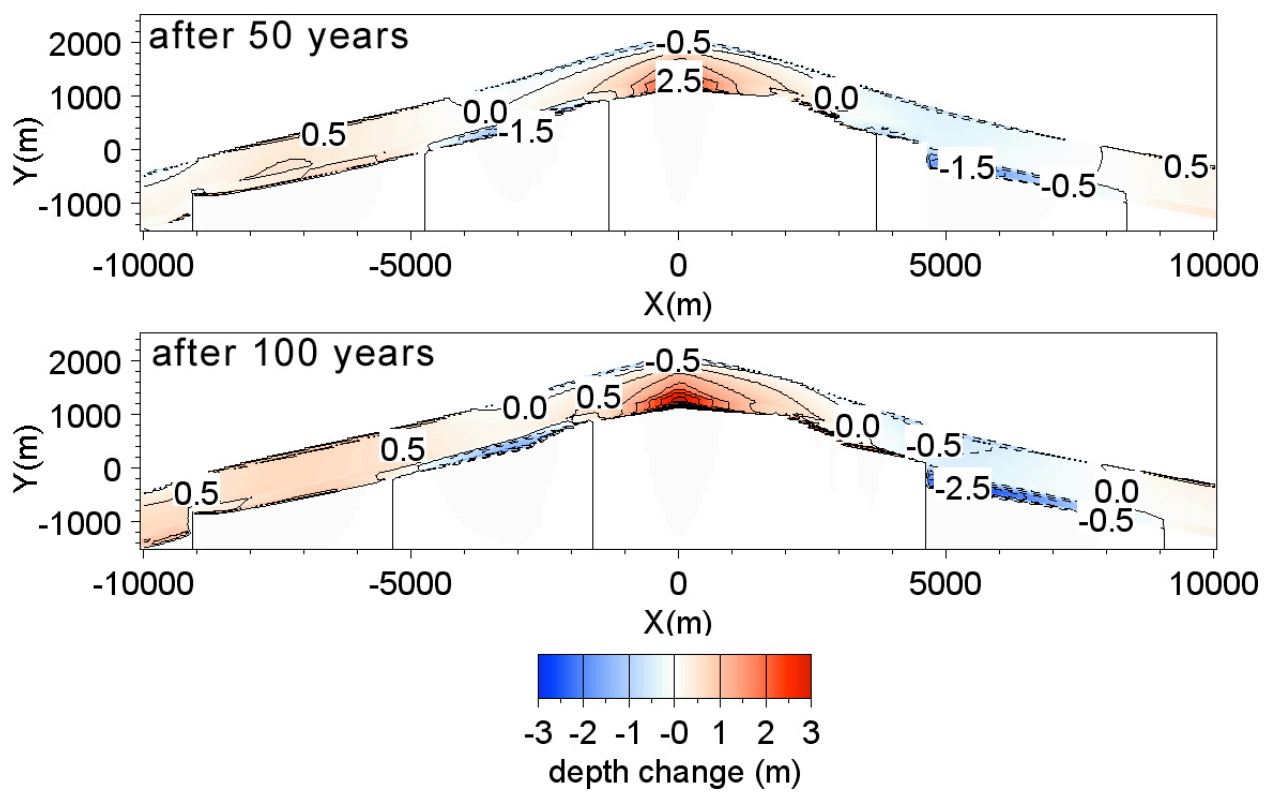

Figure 8. Topographic changes around river delta coast in case 3.
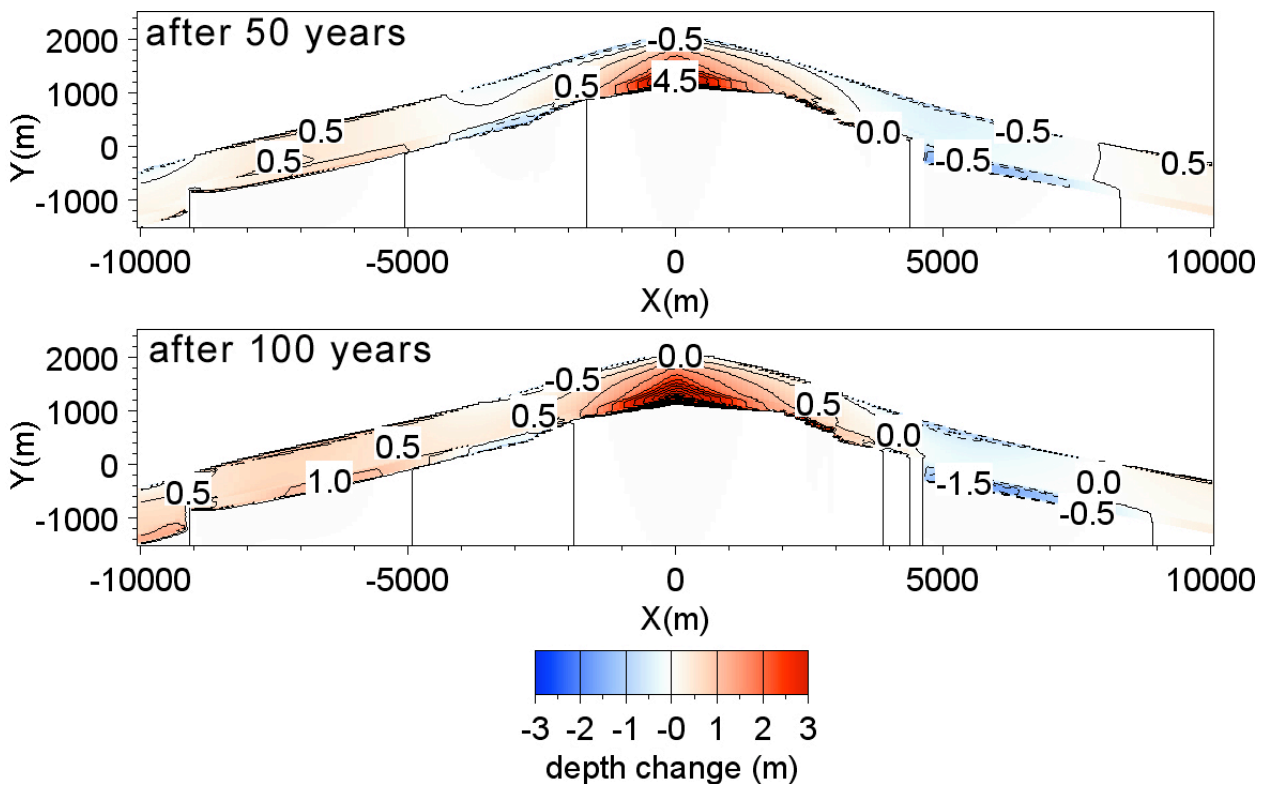

Figure 9. Topographic changes around river delta coast in case 4.

results for case 1 with no measures adopted, sand starts to be deposited within a distance of $1.5 \mathrm{~km}$ from the river mouth because of an increase in sand supply, whereas on both sides of this sand deposition zone, erosion occurs. Particularly severe beach erosion occurs west of the Magome River mouth, even though sand was supplied from the river mouth. Thus, the effect of sand bypassing in case 1 , in which sand is supplied at a rate of $2.6 \times 10^{5} \mathrm{~m}^{3} / \mathrm{yr}$, is limited because the amount of sand supply is small.

Figure 8 shows the predicted topographic changes in case 3, in which sediment with $57 \%$ fine sand, $41 \%$ medium sand and $2 \%$ coarse sand is supplied at a rate of $3.3 \times 10^{5} \mathrm{~m}^{3} / \mathrm{yr}$. Sand deposition in a triangular zone centered at the river mouth increases compared with case 2 because of the increase in the rate of sediment supply. As a result, erosion of the Ryuyo coast was mitigated and the erosion zone was narrowed, whereas erosion continues to occur west of the Magome River mouth, similar to case 1 
with no measures adopted, and the effect of increasing sediment supply does not appear, because of the blockage of westward longshore sand transport by detached breakwaters.

Figure 9 shows the predicted topographic changes in case 4, in which sediment with $55 \%$ fine sand, $43 \%$ medium sand and $2 \%$ coarse sand is supplied at a rate of $3.9 \times 10^{5} \mathrm{~m}^{3} / \mathrm{yr}$. Compared with the results of case 2 , the erosion zone east of the river mouth almost disappeared owing to sand supply and sand begins to be supplied to the west of the detached breakwaters, resulting in the mitigation of erosion west of the Magome River mouth.

Figure 10 shows the predicted topographic changes in case 5, in which sediment with $53 \%$ fine sand, $46 \%$ medium sand and $2 \%$ coarse sand is supplied at a rate of $5.2 \times 10^{5} \mathrm{~m}^{3} / \mathrm{yr}$. Since this rate of sediment supply is close to the natural rate of sediment supply, $6.0 \times 10^{5} \mathrm{~m}^{3} / \mathrm{yr}$, of the Tenryu River, sand starts to be deposited in the entire area on both sides of the river mouth.

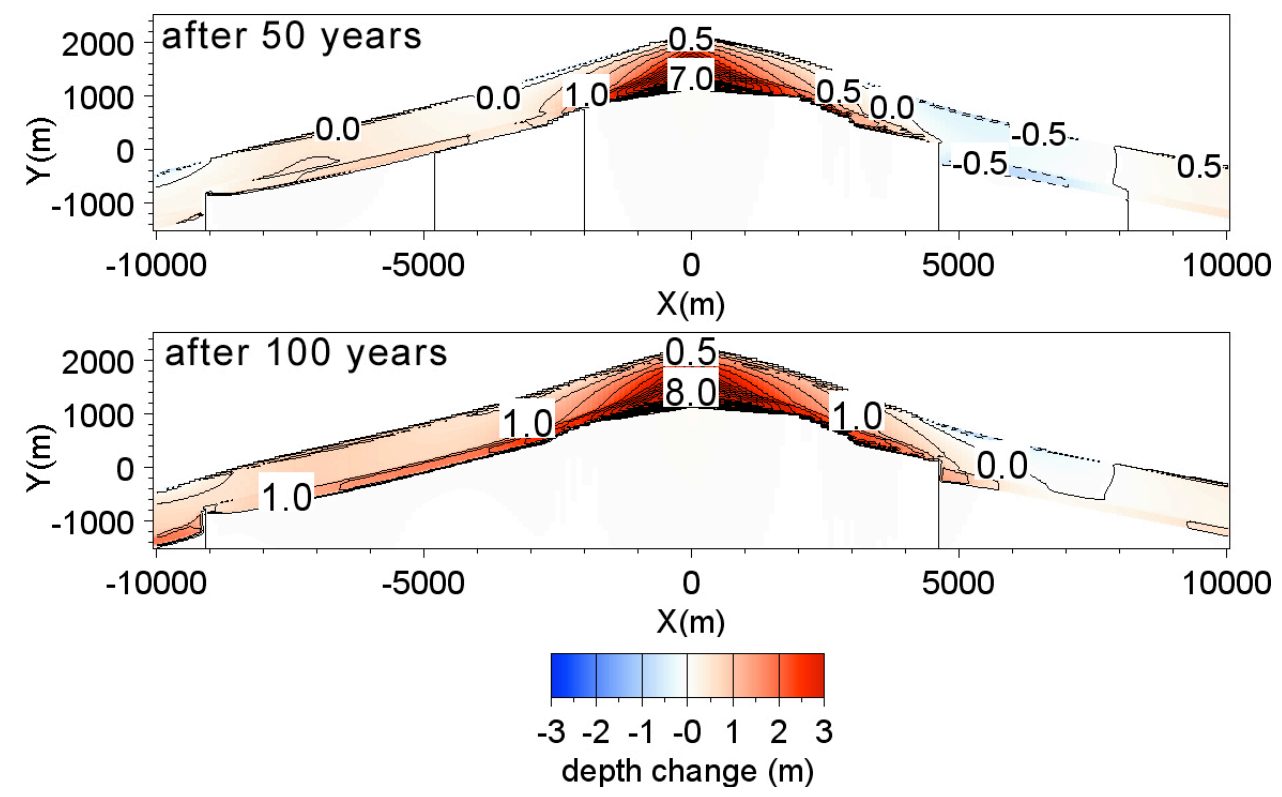

Figure 10. Topographic changes around river delta coast in case 5.

Figure 11 shows the shoreline changes over 100 years in the zone with a $10 \mathrm{~km}$ stretch on both sides of the river mouth, with reference to the shoreline in 2005. In case 1 with no measures adopted, the shoreline retreats in the zone within $\pm 5 \mathrm{~km}$ from the river mouth and shoreline recession gradually increases with time. Moreover, stepped shoreline recession occurs immediately west of the Magome River mouth because of the blockage of longshore sand transport by the river mouth jetty (Fig. 11(a)). In case 2 , the shoreline recession at the Tenryu River mouth is reduced because the rate of sediment supply increases from $1.5 \times 10^{5} \mathrm{~m}^{3} / \mathrm{yr}$ to $2.6 \times 10^{5} \mathrm{~m}^{3} / \mathrm{yr}$ (Fig. 11(b)). Compared with the result for case 1 with no measures adopted, it is clear that a shoreline advance localized at the river mouth starts to occur.

In case 3 , the features observed in case 2 become more prominent and the shoreline around the river mouth advances maintaining a triangular shape (Fig. 11(c)). The shoreline recession in a zone west of the Magome River mouth, however, is the same as those in case 1 with no measures adopted and case 2 . In case 4 , the shoreline projection of the river delta coast became more prominent owing to the increase in the rate of sediment supply, resulting in a large shoreline projection within the zone \pm 1 $\mathrm{km}$ from the river mouth (Fig. 11(d)). Furthermore, the shoreline recession near the Magome River is significantly reduced. In case 5, in which sediment is supplied at a rate of $5.2 \times 10^{5} \mathrm{~m}^{3} / \mathrm{yr}$, which is $87 \%$ of the total sediment supply under natural conditions before the anthropogenic changes, a marked effect of the increase in sediment supply can be expected (Fig. 11(e)). The shoreline advances a maximum of $450 \mathrm{~m}$ at the river mouth after 100 years, and the entire beach becomes accretive on both sides of the river mouth, indicating the effectiveness of sand nourishment on the nearby coast, along with the ssupply of sand to the coast west of the Magome River mouth. Note that sand accumulation is 
(a) case 1

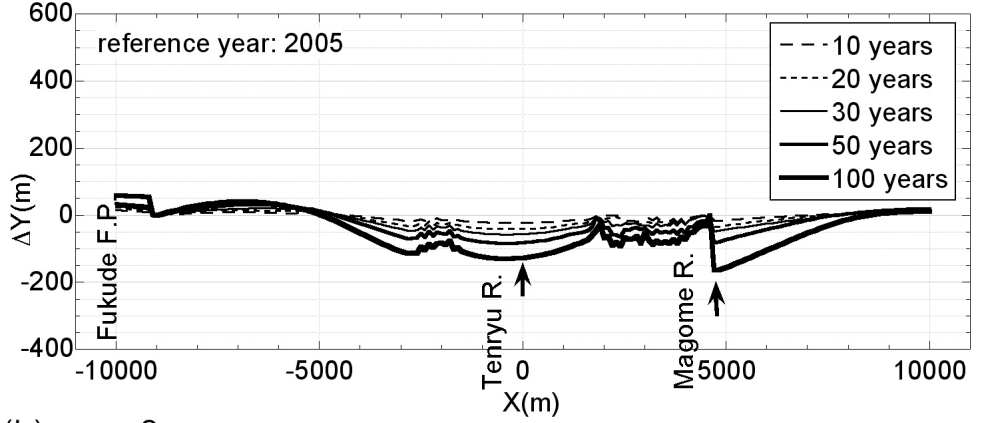

(b) case 2

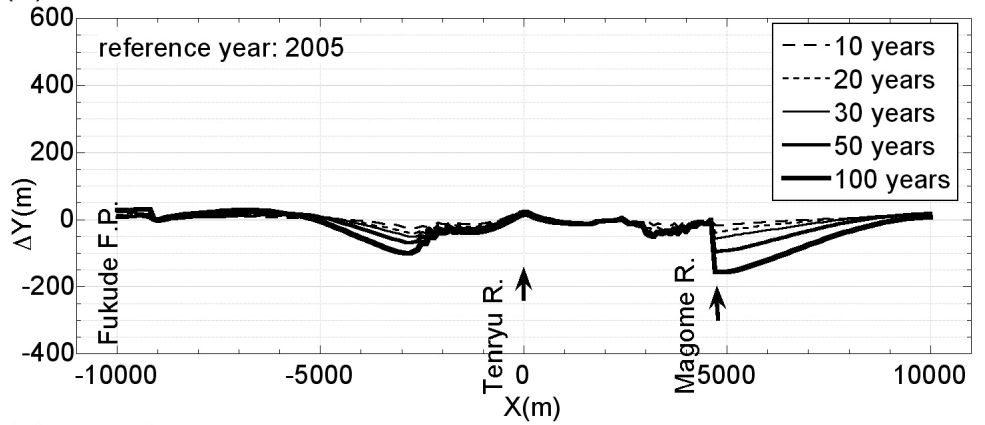

(c) case 3

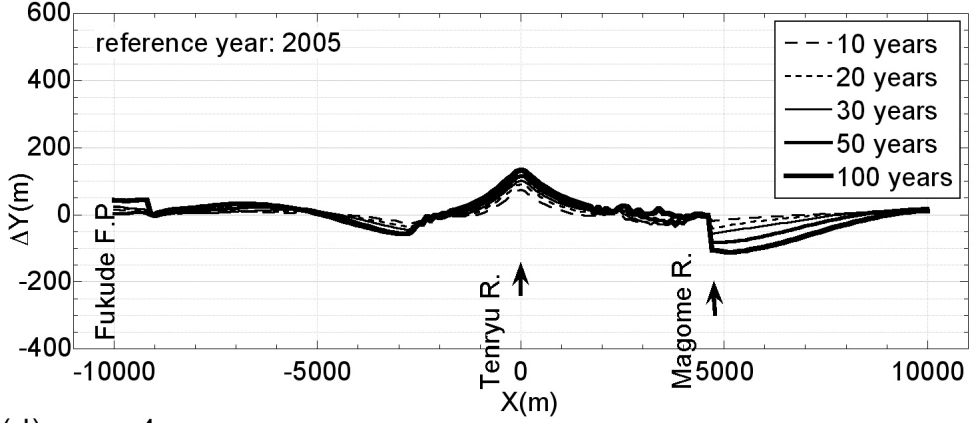

(d) case 4

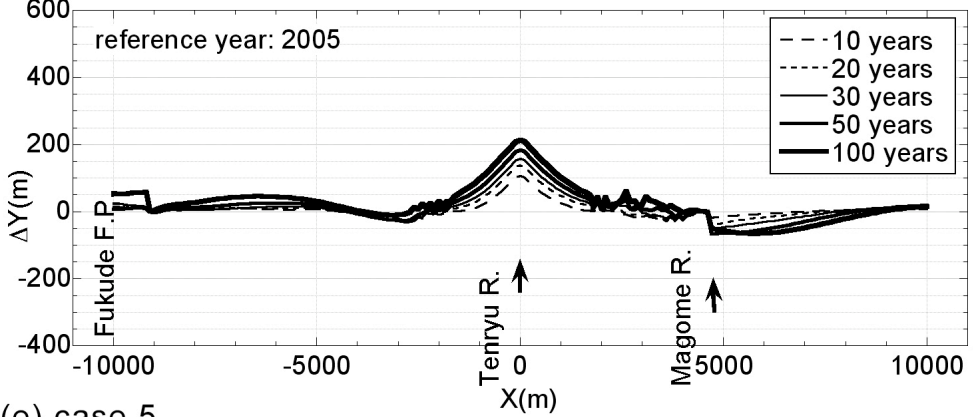

(e) case 5

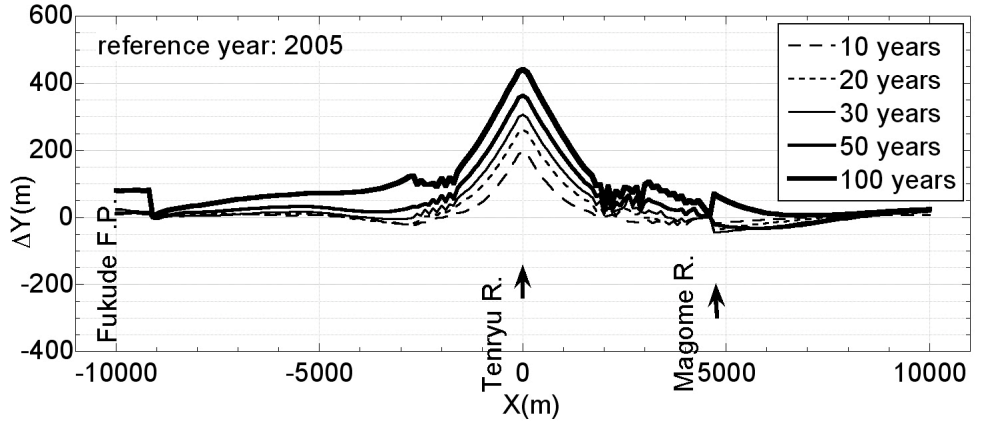

Figure 11. Shoreline changes in cases 1-5 with reference to that in 2005. 
concentrated around the river mouth and that longshore sand can only be supplied to coasts far from the river mouth only after a sufficient volume of sand is deposited in the river mouth area.

\section{CONCLUSIONS}

The effect of sand bypassing at a dam reservoir as a measure against beach erosion on a delta coast was investigated. Even though such a measure is taken to recover the sandy beach, detached breakwaters previously constructed as a measure against beach erosion are a barrier to the smooth movement of sand by westward longshore sand transport. This means that further sand bypassing on the coast, in which sand is transported from upcoast to downcoast of the detached breakwaters, is also necessary for a significantly long period to mitigate the downcoast erosion. Thus, once a continuous sand supply is interrupted, another measure is required to prevent downcoast erosion when coastal structures block longshore sand transport. The overall comprehensive management of sand supply not only in the river basin but also on the coast is necessary, unless the coastal structures built to protect the coastline are demolished (Torii et al., 2004).

\section{ACKNOWLEDGMENT}

In this study, field data was supplied by Hamatsu River and Road Office, Chubu Regional Bureau, Ministry of Infrastructure, Land and Traffic. The authors would like to express their sincere gratitude to this office.

\section{REFERENCES}

Furuike, K., T. Uda, M. Serizawa, T. San-nami and T. Ishikawa. 2009. Model for predicting long-term beach changes originated from accretive features of a natural delta coast, Asian and Pacific Coasts 2009, Proc. 5th Inter. Conf., Vol. 4, 266-272.

Kamphuis, J. W., M. H. Davies, R. B. Narim and O. J. Sayao. 1986. Calculation of littoral sand transport rate, Coastal Engineering, Vol. 10, 1-12.

Kraus, N. C. 1985. Field experiments on vertical mixing of sand in the surf zone, J. Sedimentary Petrology, Vol. 55, 3-14.

Kumada, T., A. Kobayashi, T. Uda and M. Serizawa. 2003. Development of predictive model of shoreline and grain size changes, Coastal Sediments '03, 1-14.

Ozasa, H. and A. H. Brampton. 1980. Model for predicting the shoreline evolution of beaches backed by seawalls, Coastal Eng., 4, 47-64.

Serizawa, M., T. Uda, T. San-nami, K. Furuike and T. Kumada. 2003. Improvement of contour line change model in terms of stabilization mechanism of longitudinal profile, Coastal Sediments '03, $1-15$.

Torii, K., S. Sato, T. Uda and T. Okayasu. 2004. Regional sediment management based on sediment budget for graded sediments - a case study of Tenryu watershed and Enshu-nada coast, Proc. 29th ICCE, 3110-3122.

Uda, T. and S. Kawano. 1996. Development of a predictive model of contour line change due to wave, Proc. JSCE, No. 539/ II -35, 121-139. (in Japanese)

Uda, T., T. Kumada and M. Serizawa. 2004. Predictive model of change in longitudinal profile in beach nourishment using sand of mixed grain size, Proc. 29th ICCE, 3378-3390.

Uda, T., I. Nagashima, K. Furuike, S. Miyahara and T. Ishikawa. 2008. Impact of sand bypassing at dams in Tenryu River to nearby coasts, Annual Jour. Coastal Eng., JSCE, Vol. 55, 656-660. (in Japanese) 